\title{
SELO CASA AZUL CERTIFICAÇÃO AMBIENTAL ESTUDO DE CASO: CONDOMÍNIO NEO NITERÓI
}

\author{
Camila Dinamarco \\ Mestra em Engenharia Ambiental pela Universidade Federal do Rio de Janeiro (UFRJ) \\ Programa de Engenharia Ambiental - PEA \\ \cpgcamila@gmail.com
}

\author{
Assed Haddad \\ Prof. Dr. Universidade Federal do Rio de Janeiro (UFRJ) \\ Universidade Federal Fluminense (UFF) \\ Ana Evangelista \\ Prof $^{\mathrm{a}} \mathrm{Dr}^{\mathrm{a}}$ Universidade Federal do Rio de Janeiro (UFRJ)
}

\begin{abstract}
Resumo:
O objetivo do presente estudo é realizar uma avaliação da viabilidade de aquisição do Selo Casa Azul por parte do condomínio Neo Niterói, desta maneira, avaliar se o condomínio pode ou não adquirir o Selo Casa Azul. Como justificativa tem-se que a grande parte das atividades humanas que impactam o meio ambiente tem ligações com a indústria da construção civil, e esta indústria, bem como o espaço construído, tem impactos dominantes em aspectos econômicos, sociais e ambientais. Atualmente, considerando a preocupação cada vez maior com as questões ambientais, torna-se necessário pesquisar novas alternativas para minimizar o impacto ambiental no setor da construção civil. Para tanto, a metodologia utilizada para o desenvolvimento deste estudo refere-se a revisão bibliográfica e ao estudo de caso para validar o referencial teórico disponibilizado na literatura técnica atual. A revisão bibliográfica se deu por meio de artigos científicos, normas técnicas e publicações nacionais e internacionais. O estudo de caso foi realizado em um condomínio residencial na cidade de Niterói.Constatou-se que o condomínio estaria apto a possível aquisição do Selo Casa Azul na gradação de nível Prata, caso atendesse a alguns critérios obrigatórios, descritos no Guia do Selo Casa Azul.
\end{abstract}

Palavras-chave: Selo Casa Azul; Construção civil; Certificação ambiental; Sustentabilidade; Meio ambiente.

\section{BLUE HOUSE SEAL ENVIRONMENTAL CERTIFICATION CASE STUDY: CONDOMINIUM NEO NITERÓI.}

\begin{abstract}
:
The aim of this study is to assess the feasibility of acquiring the" Selo Casa Azul - CEF" certification by the condominium Neo Niterói, in this way, the condominium can assess whether or not to purchase the "Selo Casa Azul". As justification for the development of this study, it is important to consider the impact of human activities to the environment has ties to
\end{abstract}


the construction industry. This industry, and even the built environment generally has dominant impact on economic, social aspects and environmental. The concern with environmental issues is increasing and it is necessary to investigate new environmentally friendly alternatives to be employed in civil construction industry. Therefore, the methodology used for the development of this study consists in literature review and case study to validate the theoretical material available in the current technical literature. The literature review was through scientific articles and national and international publications. . The case study was conducted in a residential condominium in the city of Niteroi. It was found that the condo would be able to possible acquisition of "Selo Casa Azul" the Silver level of gradation, if would meet some mandatory criteria described in the "Selo Casa Azul" Guide.

Keywords: Blue House Seal; Building; Environmental Certification; Sustainability; Environment.

\section{SELLO DE LA CASA AZUL DE CERTIFICACIÓN AMBIENTAL ESTUDIO DE CASO: CONDOMINIO NEO NITERÓI}

\section{Resumen:}

El objetivo de este estudio es evaluar la posibilidad de adquirir el Sello azul de la casa por el condominio Neo Niterói, de esta manera, para evaluar si la comunidad puede o no puede llegar a la Casa sello azul. Como justificación ha sido que una gran parte de las actividades humanas que afectan el medio ambiente tiene vínculos con la industria de la construcción, y esta industria, así como el entorno construido, tiene impacto dominante en los aspectos económicos, sociales y medioambientales. En la actualidad, dada la creciente preocupación por los problemas ambientales, es necesario buscar nuevas alternativas para minimizar el impacto ambiental en el sector de la construcción. Por lo tanto, la metodología utilizada para el desarrollo de este estudio se refiere a la revisión de la literatura y estudio de caso para validar el marco teórico disponible en la literatura técnica actual. La revisión de la literatura fue a través de artículos científicos, normas técnicas y publicaciones nacionales e internacionales. El estudio de caso se llevó a cabo en un condominio residencial en la ciudad de Niteroi.Se encontró que el condominio sería capaz de posible adquisición de la Casa Azul Sello de plata del nivel de gradación, si se reuniría algunos criterios obligatorios descritos en la Guía Sello de la Casa Azul.

Palabras clave: Sello de la Casa Azul; Arquitectura; Certificación Ambiental; Sostenibilidad, Medio Ambiente.

\section{INTRODUÇÃO}

Em 2007, foi criado o Green Building Council Brasil (GBC), que é uma organização não governamental que promove a capacitação de empresas para aquisição de certificações na área de construções sustentáveis. Criado pelos EUA através da US Green Building Council, o LEED (Leadership in Energy and Environmental Design) é um selo verde voltado para 
edificações que seguem modelos internacionais de sustentabilidade. Aqui no Brasil o LEED vem sendo implantado pelo GBC Brasil. O LEED é o selo mais importante na área de construção sustentável ao redor do mundo.

No ano de 2010 a Caixa Econômica Federal criou o Guia de Sustentabilidade Ambiental do Selo Casa Azul. Este guia tem a finalidade de instruir profissionais, estudantes e empresas voltadas para área de construção civil a desenvolver projetos sustentáveis com o objetivo final de aquisição do Selo Casa Azul (JOHN e PRADO, 2010).

\section{Tema e delimitação do problema}

Um dos primeiros conceitos de sustentabilidade surgiu no ano de 1987, por meio do Relatório Brundtland, que é o documento intitulado Nosso Futuro Comum (Our Common Future) tendo sido elaborado pela Comissão Mundial sobre Meio Ambiente e Desenvolvimento, criada pela Organização das Nações Unidas (ONU). O documento deu origem ao termo Desenvolvimento Sustentável, que se refere ao desenvolvimento que satisfaz as necessidades presentes, sem comprometer a capacidade das gerações futuras de suprir suas próprias necessidades. As questões ambientais são discutidas no mundo inteiro, sendo assim, a arquitetura precisou se adequar a esta demanda. Vários países criaram sistemas para avaliação de construções sustentáveis. Os sistemas para avaliação ambiental de edifícios surgiram na década de 1990 na Europa, EUA e Canadá com a finalidade de induzir o mercado de construção civil a obter níveis considerados de desempenho ambiental. Como as agendas ambientais são variadas, os métodos utilizados em outros países não deverão ser aplicados sem as devidas adaptações, incluindo a definição das exigências de sustentabilidade que deverão ser atendidas pelos edifícios no Brasil. Alguns países europeus, além de Estados Unidos, Canadá, Austrália, Japão e Hong Kong, possuem um sistema de certificação de edifícios. No Brasil, o sistema de avaliação ambiental mais conhecido é a Certificação LEED do GBC ou Selo Verde, criado pelo USGBC. (GBC, 2014) No Brasil foi criado outro sistema de certificação, conhecido como Selo Casa Azul Caixa.

Como funciona o Selo Casa Azul? Seria fácil adquirir o Selo Casa Azul da Caixa? Qualquer empreendimento imobiliário habitacional estaria apto para adquirir a certificação da Caixa? 


\section{Selo Casa Azul da Caixa}

De acordo com a Caixa Econômica Federal (CEF), por meio do Selo Casa Azul, procura-se reconhecer os projetos de empreendimentos que comprovem suas contribuições para a diminuição de impactos ambientais, avaliados inicialmente de critérios ligados as seguintes questões: qualidade urbana, projeto e conforto, eficiência energética, conservação de recursos materiais, gestão da água e práticas sociais (JOHN e PRADO, 2010).

O Selo Casa Azul CAIXA trata-se do primeiro sistema genuinamente nacional de classificação da sustentabilidade de projeto de construção civil oferecido no Brasil, desenvolvido para a realidade da construção civil do país. A metodologia do Selo foi desenvolvida por uma equipe técnica da CEF com extensa experiência em projetos habitacionais e em gerenciamento para a sustentabilidade. Um grupo multidisciplinar de doutores da Escola Politécnica da Universidade de São Paulo, Universidade Federal de Santa Catarina e Universidade Estadual de Campinas - que integrava uma rede de pesquisa financiada pelo Finep/Habitare e pela CEF - agiu como consultor, organizando, até mesmo, um workshop que teve ainda a participação de entidades representativas do mercado (JOHN e PRADO, 2010). O Selo Casa Azul trata-se de um instrumento de classificação socioambiental de projetos de empreendimentos habitacionais, que procura reconhecer os empreendimentos que seguem soluções mais competentes aplicadas à construção. Esta metodologia incide em averiguar, em meio à análise de viabilidade técnica do empreendimento, o atendimento aos critérios constituídos pelo instrumento, que instiga a adoção de práticas destinadas para a sustentabilidade dos empreendimentos habitacionais. Os níveis de graduação e pontuações mínimas podem ser observados no quadro abaixo.

Quadro 01: Níveis de gradação do Selo Casa Azul

\begin{tabular}{|l|l|}
\hline GRADAÇÃO & ATENDIMENTO MÍNIMO \\
\hline Bronze & Critérios obrigatórios \\
\hline Prata & $\begin{array}{l}\text { Critérios obrigatórios e mais seis critérios de } \\
\text { livre escolha }\end{array}$ \\
\hline Ouro & $\begin{array}{l}\text { Critérios obrigatórios e mais doze critérios de } \\
\text { livre escolha }\end{array}$ \\
\hline
\end{tabular}

Fonte: JOHN e PRADO, 2010. 
O Selo Casa Azul tem 53 critérios de avaliação, sendo 19 critérios obrigatórios para aquisição do Selo Bronze. Os Cinquenta e três critérios são distribuídos em seis categorias que norteiam a classificação do projeto, conforme pode ser visto nos quadros abaixo:

Quadro 02: Qualidade Urbana, Projeto e Conforto

\begin{tabular}{|c|c|c|c|c|}
\hline \multicolumn{5}{|c|}{ QUADRO RESUMO - CATEGORIAS, CRITÉRIOS E CLASSIFICACCÃO } \\
\hline \multicolumn{2}{|c|}{ 1. QUALIDADE URBANA } & BRONZE & PRATA & OURO \\
\hline & Qualidade do Entorno - Infraestrutura & obrigatório & \multirow{31}{*}{$\begin{array}{c}\text { critérios } \\
\text { obrigatorios } \\
+6 \text { itens de } \\
\text { livre escolha }\end{array}$} & \multirow{31}{*}{$\begin{array}{c}\text { critérios } \\
\text { obrigatorios } \\
+12 \text { itens } \\
\text { de livre escolha }\end{array}$} \\
\hline & Qualidade do Entorno - Impactos & obrigatório & & \\
\hline 1.3 & Melhorias no Entorno & & & \\
\hline 1.4 & Recuperação de Áreas Degradadas & & & \\
\hline & Reabilitaçăo de Imóveis & & & \\
\hline \multicolumn{3}{|c|}{ 2. PROJETO E CONFORTO } & & \\
\hline & Paisagismo & obrigatório & & \\
\hline & Flexibilidade de Projeto & & & \\
\hline & Relação com a Vizinhança & & & \\
\hline & Soluçăo Alternativa de Transporte & & & \\
\hline 2.5 & Local para Colota Selotiva & obrigatório & & \\
\hline & Equipamentos de Lazer, Sociais e Esportivos & obrigatório & & \\
\hline & Desempenho Térmico - Vedações & obrigatório & & \\
\hline & Desempentho Térmico - Orientaçăo ao Sol e Ventos & obrigatório & & \\
\hline 2.9 & lluminaçāo Natural de Áreas Comuns & & & \\
\hline 2.10 & Ventilaçầo e lluminaçăo Natural de Banheiros & & & \\
\hline 2.11 & Adequação às Condiçôes Fisicas do Terreno & & & \\
\hline \multicolumn{3}{|c|}{ 3. EFICIÊNCIA ENERGÉTICA } & & \\
\hline & Lámpadas de Baixo Consumo - Áreas Privativas & $\begin{array}{l}\text { obrigatório } \mathrm{p}^{\prime} \\
\text { HIS - até } 3 \mathrm{s.m} \text {. }\end{array}$ & & \\
\hline 3.2 & Dispositivos Economizadores - Áreas Comuns & obrigatório & & \\
\hline 3.3 & Sistema de Aquecimento Solar & & & \\
\hline & Sistemas de Aquecimento à Gás & & & \\
\hline & Medição Individualizada - Gás & obrigatório & & \\
\hline & Elevadores Eficientes & & & \\
\hline & Eletrodomésticos Eficientes & & & \\
\hline & Fontes Alternativas de Energia & & & \\
\hline \multicolumn{3}{|c|}{ 4. CONSERVAÇĀO DE RECURSOS MATERIAIS } & & \\
\hline & Coordenação Modular & & & \\
\hline & Qualidade de Materiais e Componentes & obrigatório & & \\
\hline & Componentes Industrializados ou Pré-fabricados & & & \\
\hline & Formas e Escoras Reutilizáveis & obrigatório & & \\
\hline
\end{tabular}

Fonte: JOHN e PRADO, 2010. 
Quadro 03: Eficiência Energética, Conservação de Recursos Materiais, Gestão da Água e Práticas Sociais

\begin{tabular}{|c|c|c|c|c|}
\hline QUADRO RESUMO - CATEGORIAS, CRITÉRIOS E CLASSIFICACCÃO & $\begin{array}{l}\text { QUADRO RESUMO - CATEGORIAS, C } \\
\text { CATEGORIAS/CRITÉRIOS }\end{array}$ & \multicolumn{3}{|c|}{ CLASSIFICAÇĀO } \\
\hline \multicolumn{2}{|r|}{ 4. CONSERVAÇĀO DE RECURSOS MATERIAIS } & BRONZE & PRATA & OURO \\
\hline 4.5 & Gestão de Residuos de Construção e Demolição (RCD) & obrigatório & \multirow{27}{*}{$\begin{array}{l}\text { critérios } \\
\text { obrigatórios } \\
+6 \text { itens de } \\
\text { livre escolha }\end{array}$} & \multirow{27}{*}{$\begin{array}{l}\text { critérios } \\
\text { obrigatórios } \\
+12 \text { itens de } \\
\text { livre escolha }\end{array}$} \\
\hline 4.6 & Concreto com Dosagem Otimizada & & & \\
\hline 4.7 & Cimento de Alto-Forno (CPIII) e Pozolânico (CP IV) & & & \\
\hline 4.8 & Pavimentação com RCD & & & \\
\hline 4.9 & Facilidade de Manutenção da Fachada & & & \\
\hline 4.10 & Madeira Plantada ou Certificada & & & \\
\hline \multicolumn{3}{|c|}{ 5. GESTÃO DA ÁGUA } & & \\
\hline 5.1 & Mediçāo Individualizada - Água & obrigatório & & \\
\hline 5.2 & Dispositivos Economizadores - Sistema de Descarga & obrigatório & & \\
\hline 5.3 & Dispositivos Economizadores - Arejadores & & & \\
\hline 5.4 & Dispositivos Economizadores - Registro Regulador de Vazão & & & \\
\hline 5.5 & Aproveitamento de Águas Pluviais & & & \\
\hline 5.6 & Retençăo de Águas Pluviais & & & \\
\hline 5.7 & Infiltração de Águas Pluviais & & & \\
\hline & Áreas Permeáveis & obrigatório & & \\
\hline \multicolumn{2}{|c|}{ 6. PRÁTICAS SOCIAIS } & & & \\
\hline & Educaçăo para a Gestăo de RCD & obrigatório & & \\
\hline 6.2 & Educaçāo Ambiental dos Empregados & obrigatório & & \\
\hline 6.3 & Desenvolvimento Pessoal dos Empregados & & & \\
\hline 6.4 & Capacitaçăo Profissional dos Empregados & & & \\
\hline 6.5 & Inclusão de trabalhadores locais & & & \\
\hline 6.6 & Participação da Comunidade na Elaboraçăo do Projeto & & & \\
\hline 6.7 & Orientação aos Moradores & obrigatório & & \\
\hline 6.8 & Educação Ambiental dos Moradores & & & \\
\hline 6.9 & Capacitaçâo para Gestão do Empreendimento & & & \\
\hline 6.10 & Açōes para Mitigação de Riscos Sociais & & & \\
\hline 6.11 & Açōes para a Geraçāo de Emprego e Renda & & & \\
\hline
\end{tabular}

Fonte: JOHN e PRADO, 2010.

\section{Como Obter o Selo Casa Azul - Orientações Gerais}

A adesão do selo casa azul é voluntária, o proponente deverá expor interesse em adquiri-lo a fim de que o projeto seja analisado sob os critérios desta certificação. Ao manifestar interesse na adesão do Selo Casa Azul, o proponente deverá apresentar à Caixa os projetos, a documentação, as informações técnicas completas referentes aos critérios a serem atendidos e também os formulários da Caixa devidamente preenchidos. Toda documentação deverá ser datada e assinada pelo representante legal e pelo responsável técnico dos projetos. Se necessário a Caixa poderá a qualquer momento solicitar correção e/ou complementação da documentação. Qualquer alteração efetuada no projeto durante a obra deverá ser comunicada 
a Caixa. Durante todo processo de certificação, o empreendimento imobiliário ficará sujeito a vistorias da Caixa.

\section{METODOLOGIA}

A metodologia utilizada para o desenvolvimento do presente estudo, inicialmente trata-se de uma revisão bibliográfica. Esta revisão bibliográfica se deu por meio de artigos científicos e publicações. Todo o material foi obtido por meio de sites de busca e bibliotecas virtuais, tais como plataforma CAPES, Google Acadêmico e SciELO. Após a fase de levantamento bibliográfico, foi realizada uma triagem de todo o material que aborda em específico o assunto em estudo. A pesquisa é do tipo estudo de caso, caracterizando-se como qualitativo descritivo. Em seguida, foi realizado um estudo de caso no condomínio Neo Niterói, na cidade de Niterói. Como instrumentos de coleta de dados, foram utilizadas câmeras fotográficas, manual do proprietário, plantas dos apartamentos, memorial descritivo do condomínio Neo Niterói e cadernos de anotações.

\section{Objetivo do Estudo de Caso}

Avaliar a viabilidade do empreendimento imobiliário Neo Niterói, ante a aquisição do Selo Casa Azul. Verificar a possibilidade de enquadramento dos edifícios residenciais em uma das gradações do Selo Casa Azul, que podem ser: Bronze, Prata ou Ouro.

\section{Descrição do Empreendimento Imobiliário - Condomínio Neo Niterói}

De acordo com o memorial descritivo do empreendimento, a Construtora Atlântica Residencial S\A, com sede na Av. Presidente Wilson, 231 salões 501 e 504 - Centro - RJ, Inscrita no CNPJ: 04.241.304/0001-00, foi a responsável pelo projeto de Construção do Condomínio Neo Niterói.

O empreendimento imobiliário é formado por 4 torres, de destinação exclusivamente residencial, sob o regime condominial regulado pela Lei Federal n. ${ }^{\circ} 4.591$ de 16/12/1964, e legislação posterior pertinente, foi obtida a aprovação junto a prefeitura da cidade de Niterói, do respectivo projeto arquitetônico, através do processo n. ${ }^{\circ}$ 80/000345/2002. As edificações foram erigidas com fiel observância ás normas da ABNT. 
O imóvel está situado na Rua Doutor Luiz Palmier, n. 280 Barreto - Niterói, é constituído de um edifício residencial, de destinação multifamiliar, denominado "Neo Niterói, composto de 4 blocos denominados de Torres. O condomínio Neo Niterói é composto de:

- Área externa: possui exclusivamente partes comuns, contendo via interna de circulação de veículos, calçadas, jardins, estacionamento descoberto para 408 veículos, área de lazer, piscina adulto, piscina infantil, deck, salão de festas com cozinha, lavabo e dois banheiros e dois sanitários/vestiários, uma guarita com banheiro, quatro edículas com churrasqueiras e quadra poliesportiva.

- Torres 1, 2, 3 e 4: O térreo de cada Torre é composto de partes comuns e privativas. Contendo como partes comuns: hall com acesso para dois elevadores, escada depósito, casa de bombas, compartimento de ECT, dois compartimentos para medidores e compartimento do lixo. Sua parte privativa é constituída de oito unidades numeradas de 101 a 108, sendo as numeradas 101, 102, 105 e 106 constituídas de hall, sala, circulação, dois quartos, banheiro, cozinha e área de serviço. As unidades numeradas como 103,104, 107 e 108 são constituídas de sala, quarto, banheiro, cozinha e área de serviço.

- Pavimentos tipo ( $2^{\circ}$ ao $13^{\circ}$ andar, nas Torres 1,2 e 3 e $2^{\circ}$ ao $12^{\circ}$ andar na Torre 4$)$ : Todos eles são constituídos de partes comuns e privativas, tendo como partes comuns: hall de acesso para dois elevadores, compartimento de lixo, escada, antecâmara e como partes privativas cada uma das oito unidades, sendo que as unidades numeradas como 201/1301, 202/1302, 205/1305 e 206/1306 das Torres 1, 2 e 3 e 201/1201, 202/1202, 205/1205 e 206/1206 da Torre 4, são constituídas de sala, circulação, dois quartos, banheiro, cozinha e área de serviço.

- Cobertura: Constituídas somente de partes comuns, contendo casa de máquinas de elevadores, casa de bomba de incêndio, escada, antecâmara, reservatório d' água e telhado.

\section{RESULTADOS}

O objetivo da pesquisa foi realizar um estudo de caso no Condomínio Neo Niterói, com a finalidade de verificar se o mesmo estaria apto para adquirir uma certificação do Selo Casa Azul da Caixa. A análise foi feita por meio de vistorias, fotos, verificação de plantas, manual do proprietário e memorial descritivo. O Guia Selo Casa Azul da Caixa foi utilizado para embasamento durante todo o processo de estudo de caso do empreendimento imobiliário. 
Conforme é descrito no guia do Selo Casa Azul, a caixa concede o selo a partir de uma análise detalhada de critérios pré-estabelecidos. O atendimento aos critérios possibilitará o enquadramento em um dos três níveis de gradação (JOHN e PRADO, 2010).

Quadro 04: Especificações dos níveis de gradação do Selo Casa Azul.

\begin{tabular}{|l|l|}
\hline GRADAÇÃO & ATENDIMENTO MÍNIMO \\
\hline BRONZE & O empreendimento imobiliário deverá atender aos 19 critérios obrigatórios \\
\hline PRATA & $\begin{array}{l}\text { O empreendimento imobiliário deverá atender aos } 19 \text { critérios obrigatórios e mais } \\
6 \text { critérios de livre escolha }\end{array}$ \\
\hline OURO & $\begin{array}{l}\text { O empreendimento imobiliário deverá atender aos } 19 \text { critérios obrigatórios e mais } \\
12 \text { critérios de livre escolha }\end{array}$ \\
\hline
\end{tabular}

Fonte: JOHN e PRADO, 2010 (adaptado).

Durante o estudo de caso foram avaliados os 53 critérios estabelecidos pela caixa, com o objetivo de identificar quais os critérios foram atendidos adequadamente pelo empreendimento imobiliário Neo Niterói. Abaixo podemos observar o quadro com o resumo desses critérios atendidos ou não pelo Neo Niterói:

Quadro 05: Critérios para aquisição do Selo Casa Azul

\begin{tabular}{|c|c|c|}
\hline $\begin{array}{l}\text { CATEGORIAS/ } \\
\text { CRITÉRIOS }\end{array}$ & DETALHE & $\begin{array}{llr}\text { OBSERVAÇÕES } & \text { QUANTO AO } \\
\text { EMPREENDIMENTO } & \text { IMOBILIÁRIO } \\
\text { NEO NITERÓI } & \end{array}$ \\
\hline \multicolumn{3}{|l|}{ QUALIDADE URBANA } \\
\hline $\begin{array}{l}\text { 1.1 Qualidade do entorno - } \\
\text { Infraestrutura }\end{array}$ & Obrigatório & Atende com sucesso \\
\hline $\begin{array}{l}1.2 \text { Qualidade do entorno - } \\
\text { Impactos }\end{array}$ & Obrigatório & Atende com sucesso \\
\hline 1.3 Melhorias no entorno & & Não atende \\
\hline $\begin{array}{l}1.4 \text { Recuperação de áreas } \\
\text { degradadas }\end{array}$ & & Não atende \\
\hline 1.5 Reabilitação de imóveis & & Não atende \\
\hline
\end{tabular}




\begin{tabular}{|c|c|c|}
\hline \multicolumn{3}{|l|}{ PROJETO E CONFORTO } \\
\hline 2.1 Paisagismo & Obrigatório & Atende com sucesso \\
\hline 2.2 Flexibilidade de projeto & & Não atende \\
\hline 2.3 Relação com a vizinhança & & Não atende \\
\hline $\begin{array}{l}2.4 \text { Solução alternativa de } \\
\text { transporte }\end{array}$ & & Atende com sucesso \\
\hline 2.5 Local para coleta seletiva & Obrigatório & Atende com sucesso \\
\hline $\begin{array}{l}2.6 \text { Equipamentos de lazer, } \\
\text { sociais e esportivos }\end{array}$ & Obrigatório & Atende com sucesso \\
\hline $\begin{array}{l}2.7 \text { Desempenho térmico - } \\
\text { Vedações }\end{array}$ & Obrigatório & Atende parcialmente \\
\hline $\begin{array}{l}2.8 \text { Desempenho térmico - } \\
\text { Orientações ao Sol e Ventos }\end{array}$ & Obrigatório & Atende parcialmente \\
\hline $\begin{array}{l}\text { 2.9 Iluminação natural de áreas } \\
\text { comuns }\end{array}$ & & Atende com sucesso \\
\hline $\begin{array}{l}2.10 \text { Ventilação e iluminação } \\
\text { natural de banheiros }\end{array}$ & & Atende com sucesso \\
\hline $\begin{array}{l}2.11 \text { Adequação ás condições } \\
\text { físicas do terreno }\end{array}$ & & Atende parcialmente \\
\hline \multicolumn{3}{|l|}{ EFICIÊNCIA ENERGÉTICA } \\
\hline $\begin{array}{l}\text { 3.1 Lâmpadas de baixo } \\
\text { consumo - Áreas privativas }\end{array}$ & $\begin{array}{l}\text { Obrigatório para } \\
\text { HIS até } 3 \text { s.m. }\end{array}$ & Atende parcialmente \\
\hline \begin{tabular}{lrr}
3.2 & \multicolumn{2}{c}{ Dispositivos } \\
economizadores & - & Áreas \\
comuns & &
\end{tabular} & Obrigatório & Atende com sucesso \\
\hline $\begin{array}{l}3.3 \text { Sistema de aquecimento } \\
\text { solar }\end{array}$ & & Não atende \\
\hline $\begin{array}{l}3.4 \text { Sistema de aquecimento á } \\
\text { gás }\end{array}$ & & Não atende \\
\hline $\begin{array}{l}\text { 3.5 Medição individualizada - } \\
\text { Gás }\end{array}$ & Obrigatório & Atende com sucesso \\
\hline
\end{tabular}




\begin{tabular}{|c|c|c|}
\hline 3.6 Elevadores eficientes & & Atende com sucesso \\
\hline 3.7 Eletrodomésticos eficientes & & Atende com sucesso \\
\hline $\begin{array}{l}3.8 \text { Fontes alternativas de } \\
\text { energia }\end{array}$ & & Não atende \\
\hline \multicolumn{3}{|c|}{ CONSERVAÇÃO DE RECURSOS MATERIAIS } \\
\hline 4.1 Coordenação modular & & Não atende \\
\hline $\begin{array}{l}4.2 \text { Qualidade de materiais e } \\
\text { componentes }\end{array}$ & Obrigatório & Atende com sucesso \\
\hline \begin{tabular}{lll}
4.3 & \multicolumn{2}{c}{ Componentes } \\
industrializados & ou pré- \\
fabricados & &
\end{tabular} & & Atende com sucesso \\
\hline $\begin{array}{l}4.4 \text { Formas e } \\
\text { reutilizáveis }\end{array}$ & Obrigatório & Atende parcialmente \\
\hline $\begin{array}{l}4.5 \text { Gestão de resíduos de } \\
\text { construção e demolição }\end{array}$ & Obrigatório & Atende parcialmente \\
\hline $\begin{array}{l}4.6 \text { Concreto com dosagem } \\
\text { otimizada }\end{array}$ & & Não atende \\
\hline $\begin{array}{l}4.7 \text { Cimento de alto-forno } \\
\text { (CPIII) e Pozolânico (CPIV) }\end{array}$ & & Não atende \\
\hline 4.8 Pavimentação com RCD & & Não atende \\
\hline $\begin{array}{l}\text { 4.9 Facilidade de manutenção } \\
\text { da fachada }\end{array}$ & & Atende com sucesso \\
\hline $\begin{array}{l}4.10 \text { Madeira plantada ou } \\
\text { certificada }\end{array}$ & & Não atende \\
\hline \multicolumn{3}{|l|}{ GESTÃO DA ÁGUA } \\
\hline $\begin{array}{l}5.1 \text { Medição individualizada - } \\
\text { Água }\end{array}$ & Obrigatório & Não atende \\
\hline $\begin{array}{l}5.2 \quad \text { Dispositivos } \\
\text { economizadores }- \text { Sistema de } \\
\text { descarga }\end{array}$ & Obrigatório & Atende com sucesso \\
\hline
\end{tabular}




\begin{tabular}{|c|c|c|}
\hline $\begin{array}{l}5.3 \quad \text { Dispositivos } \\
\text { economizadores - Arejadores }\end{array}$ & & Atende com sucesso \\
\hline 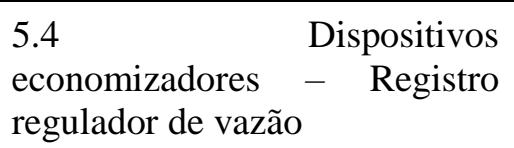 & & Atende com sucesso \\
\hline $\begin{array}{l}5.5 \text { Aproveitamento de águas } \\
\text { pluviais }\end{array}$ & & Não atende \\
\hline 5.6 Retenção de águas pluviais & & Atende parcialmente \\
\hline $\begin{array}{l}5.7 \text { Infiltração de águas } \\
\text { pluviais }\end{array}$ & & Não atende \\
\hline 5.8 Áreas permeáveis & Obrigatório & Atende com sucesso \\
\hline \multicolumn{3}{|l|}{ PRÁTICAS SOCIAIS } \\
\hline $\begin{array}{l}\text { 6.1 Educação para gestão de } \\
\text { RCD }\end{array}$ & Obrigatório & Não atende \\
\hline $\begin{array}{l}6.2 \text { Educação ambiental dos } \\
\text { empregados }\end{array}$ & Obrigatório & Não atende \\
\hline $\begin{array}{l}\text { 6.3 Desenvolvimento pessoal } \\
\text { dos empregados }\end{array}$ & & Não atende \\
\hline $\begin{array}{l}\text { 6.4 Capacitação profissional } \\
\text { dos empregados }\end{array}$ & & Não atende \\
\hline $\begin{array}{l}6.5 \text { Inclusão de trabalhadores } \\
\text { locais }\end{array}$ & & Não atende \\
\hline $\begin{array}{lll}6.6 & \text { Participação } & \text { da } \\
\text { comunidade na elaboração } & \text { do } \\
\text { projeto } & & \end{array}$ & & Não atende \\
\hline 6.7 Orientação aos moradores & Obrigatório & Atende \\
\hline $\begin{array}{l}6.8 \text { Educação ambiental dos } \\
\text { moradores }\end{array}$ & & Atende parcialmente \\
\hline $\begin{array}{l}\text { 6.9 Capacitação para gestão do } \\
\text { empreendimento }\end{array}$ & & Atende parcialmente \\
\hline
\end{tabular}




\begin{tabular}{|l|l|l|}
\hline $\begin{array}{l}6.10 \text { Ações para mitigação de } \\
\text { riscos sociais }\end{array}$ & Não atende \\
\hline $\begin{array}{l}\text { 6.11 Ações para geração de } \\
\text { empregos e renda }\end{array}$ & Não atende \\
\hline
\end{tabular}

Fonte: JOHN e PRADO, 2010 (adaptado).

Conforme podemos observar no quadro acima, o projeto do condomínio Neo Niterói atende a 16 critérios obrigatórios e também atende a 13 critérios eletivos. Os critérios atendidos somam um total de 29 dos 53 critérios especificados.

Para o Neo Niterói pleitear o Selo Casa Azul junto a Caixa, seria necessário atender aos 3 critérios obrigatórios pendentes, que são:

- 5.1 Medição individualizada - Água

- 6.1 Educação para gestão de RCD

- 6.2 Educação ambiental dos empregados

Para atende ao critério 5.1 seria necessário um novo projeto para implantação de medidores individualizados de água. Tendo em vista que os prédios já estão construídos, a implantação de um novo projeto deverá passar por uma assembléia geral de condomínio para ser aprovado. Os medidores individualizados de água acarretariam uma redução significativa na taxa de condomínio mensal, pois cada condômino passaria a pagar sua água à parte. Assim cada um reduziria seu consumo, pagando apenas pelo que usasse.Para atender aos critérios 6.1 e 6.2, durante a obra deveriam ter sido implantados projetos de educação para gestão de resíduos de construção e demolição, bem como, projetos de educação ambiental direcionados aos empregados.Se os critérios 5.1, 6.1 e 6.2 não fossem obrigatórios, seria possível pleitear junto à Caixa o Selo Casa Azul na categoria PRATA para o projeto imobiliário do Neo Niterói, embasando-se na perspectiva de o empreendimento imobiliário ter atendido um total de 30 critérios.

\section{DISCUSSÃO / ANÁLISE DE DADOS}

\section{Critérios atendidos versus benefícios adquiridos}

O crescimento significativo da população mundial, o êxodo rural, o desenvolvimento produtivo, aumento da produção de bens de consumo, a demanda pelo consumo e melhor 
qualidade de vida, vem acarretando uma série de problemas ambientais e um desequilíbrio ecológico.Com o crescimento da economia faz-se necessário a construção de novos aeroportos, ferrovias, estradas, redes de distribuição elétrica e também moradias para a população. $\mathrm{O}$ desenvolvimento dessas construções gera um desequilíbrio muito grande no meio ambiente, visto que se faz necessário o uso excessivo de matérias-primas extraídas do ambiente.A construção civil é um dos principais consumidores de matérias-primas e grande parte destas, são fontes de recursos de materiais não renováveis. A construção civil é também uma das maiores fontes geradoras de resíduos para o meio ambiente.

Nos EUA estimam-se que $70 \%$ dos materiais consumidos vão para construção civil (Matos e Wagner, 1998).

Estima-se que entre a metade a três quartos dos materiais extraídos da natureza retornam como resíduos em um período de 1 ano (MATTHEWSet al., 2014).

No Brasil, segundo Scheniniet al.(2004), inexistência de uma consciência ecológica na indústria da construção civil resultou em danos ambientais irreparáveis, que foram agravados pelo maciço processo de migração ocorrido na segunda metade do século passado, que ocasionou uma enorme demanda por novas habitações.

Atualmente, o modelo de construção civil praticado no Brasil, em toda a sua cadeia de produção, ocasiona vários prejuízos ambientais, pois, além de utilizar, amplamente, matériaprima não renovável da natureza e consumir elevadas quantidades de energia, tanto na extração quanto no transporte e processamento dos insumos, é também perdulário no uso dos materiais e considerado grande fonte geradora de resíduos dentro da sociedade. (ROTH e GARCIAS, 2009).

A construção civil precisa se voltar urgente para a utilização de práticas mais sustentáveis, evitar o consumo excessivo e indiscriminado de matérias-primas não renováveis, observar o ciclo de vida dos materiais utilizados, fazer a reutilização dos resíduos de construção e demolição, quando não for possível reutilizar os RCD fazer a destinação final adequada do mesmo, buscar utilizar técnicas de fontes de energia limpa e principalmente se emprenhar em desenvolver projetos sustentáveis que contribuam para a recuperação do meio ambiente.

Através da proposta da Caixa, que visa à implantação do Selo Casa Azul nos empreendimentos imobiliários do Brasil, será possível contribuir para a conscientização e necessidade de implantação de moradias sustentáveis que não agridam o meio ambiente.Cada critério adotado pela Caixa para determinar a possível aquisição de uma das gradações do 
Selo Casa Azul foi pensado em práticas mais sustentáveis durante a construção e também imóveis mais sustentáveis que reduzem o consumo de energia. (JOHN e PRADO, 2010).

\section{Benefícios adquiridos com os critérios atendidos pelo empreendimento} imobiliário Neo Niterói:

Critério 1.1 Qualidade do entorno - Infraestrutura: Através do atendimento a este critério, foi possível proporcionar aos moradores do Neo Niterói grande qualidade de vida, visto que o mesmo está localizado em uma área próxima à comércios, igrejas, postos de saúde, escolas, parque Palmier Silva (horto do Barreto), pontos de ônibus, entre outros.

Critério 1.2 Qualidade do entorno - Impactos: O atendimento deste critério proporcionou aos moradores do Condomínio qualidade de vida, pois o mesmo foi construído distante de fábricas, indústrias, estações de tratamento de água, aeroportos, rodovias, o que caracteriza a inexistência de poluição sonora, auditiva, visual e do ar ao entorno.

Critério 1.3 Paisagismo: Em atendimento a este critério, o Neo Niterói conta com um projeto de paisagismo muito bem empregado, possui diversas árvores espalhas pelo condomínio, inclusive árvores frutíferas, que proporcionam sombra para os moradores e deixam o ambiente mais fresco e aconchegante.

Critério 1.4 Relação com a vizinhança: Em atendimento a este critério, o empreendimento imobiliário Neo Niterói foi construído estrategicamente posicionado de maneira a não impactar negativamente na vizinhança. $O$ condomínio não obstrui a luminosidade nem a incidência de ventos nas edificações vizinhas, está posicionado a uma distância considerável das edificações vizinhas a fim de estabelecer a privacidade dos outros.

Critério 1.5 Solução alternativa de transporte: Em atendimento a este critério, o Neo Niterói foi construído próximo a ciclovias e também conta com um bicicletário para utilização dos moradores. Esse é um grande diferencial, pois permite que os moradores se desloquem facilmente pelo bairro do Barreto inclusive seguir para o centro de Niterói usando como meio de transporte uma bicicleta, que não polui o meio ambiente.

Critério 1.6 Local para coleta seletiva: Em atendimento a este critério, o condomínio conta com um espaço fora do condomínio, onde é feita toda separação de resíduos orgânicos, plástico, papel, vidro e metais do lixo gerado pelos moradores. Após a separação parte do lixo separado é encaminhado para coleta e posteriormente direcionado ao aterro sanitário pela companhia de limpeza local e todo papelão separado é vendido para uma cooperativa de reciclagem. O lucro obtido através dessa venda é revertido em melhorias para o condomínio. A separação do lixo possibilita a reciclagem, favorecendo o meio ambiente de maneira geral. 
Critério 1.7 Equipamentos de lazer, sociais e esportivos: Em atendimento a este critério, o condomínio conta com quadra poliesportiva, piscina de adulto e infantil, salão de festas, parquinho infantil, academia ao ar livre e espaço de convivência. Todas essas estruturas permitem que os moradores tenham bastante entretenimento, sejam estimulados a ter uma vida mais saudável ao praticar exercícios e esportes, bem como, manter o bom relacionamento interpessoal entre os vizinhos.

Critério 1.8 Desempenho térmico - Vedações: Em atendimento a este critério, o condomínio conta com bom desempenho térmico em relação às vedações. Em virtude das paredes e revestimentos terem sido construídas de maneira adequada ao clima local, proporciona uma grande eficiência energética. Os cômodos permanecem com clima agradável durante todo ano. Nem sempre é necessário ligar ventilador ou ar condicionado. As paredes dos apartamentos não dissipam o calor para o interior do mesmo.

Critério 1.9 Desempenho térmico - Orientação ao Sol e Ventos: Em atendimento a este critério, o condomínio Neo Niterói conta com bom desempenho térmico em relação à incidência de Sol e Ventos. Os cômodos permanecem com clima agradável durante todo ano, pois o Sol incide apenas em uma parte do dia e os apartamentos recebem muita ventilação natural devido seu posicionamento próximo a Baía de Guanabara. Nem sempre é necessário ligar ventilador ou ar condicionado e isso possibilita grande economia na conta de luz dos moradores.

Critério 1.10 Iluminação natural de áreas comuns: Em atendimento a este critério, o Neo Niterói conta com apartamentos muito bem favorecidos por iluminação natural. Os apartamentos recebem iluminação natural durante o dia inteiro, isso se deve ao fato de possuírem janelas com vão adequado a incidência de iluminação. Por esse motivo não é necessário acender lâmpadas durante o dia, o que acarreta numa economia significativa na conta de luz.

Critério 1.11 Ventilação e iluminação natural de banheiros: Em atendimento a este critério, todos os banheiros dos apartamentos do Neo Niterói contam com uma báscula de 30x30cm que permite a incidência de luminosidade e ventilação do mesmo. Durante o dia é possível economizar energia elétrica, pois a incidência de luminosidade dentro do banheiro permite a utilização do mesmo sem a necessidade de acender uma lâmpada.

Critério 1.12 Adequação as condições físicas do terreno: Em atendimento a este critério, o condomínio Neo Niterói foi construído após um processo de terraplanagem do terreno, no qual se preservou várias pedras existentes no mesmo. Inclusive a piscina foi 
construída sobre uma grande pedra, essa iniciativa possibilitou não danificar o espaço natural pré-existente no terreno, mantendo parte dele preservada originalmente.

Critério 1.13 Lâmpadas de baixo consumo - Áreas privativas: Em atendimento a este critério os apartamentos do Neo Niterói utilizam lâmpadas de baixo consumo como florescentes e led, o que acarreta uma diminuição no consumo de energia e consequente redução do valor final da conta de luz dos moradores.

Critério 1.14 Dispositivos economizadores - Áreas comuns: Em atendimento a este critério o empreendimento imobiliário conta com dispositivos economizadores de energia instalados em áreas comuns. São sensores de presença, que fazem as lâmpadas acender apenas na presença de pessoas transitando, na ausência de pessoas esses sensores mantêm as lâmpadas desligadas. Essa iniciativa proporciona uma economia de energia significativa para o condomínio.

Critério 1.15 Medição individualizada - Gás: Em atendimento a este critério, cada apartamento do Neo Niterói possui seu próprio medido individualizado de gás. As instalações de gás são apenas para uso do fogão. Os medidores individualizados de gás possibilitam aos moradores um controle maior dos gastos e acaba incentivando a redução do consumo.

Critério 1.16 Elevadores eficientes: Em atendimento a este critério, o condomínio conta com um controle de tráfego eficiente dos elevadores das torres. Cada torre conta com dois elevadores durante o dia e parte da noite. Durante a madrugada cada torre conta com apenas um elevador, pois os outros são desligados das $24 \mathrm{~h}$ às $6 \mathrm{~h}$, onde há menor demanda para uso dos mesmos. Essa iniciativa permite uma redução no consumo de energia, visto que quatro elevadores permanecem desligados durante toda madrugada.

Critério 1.17 Eletrodomésticos eficientes: Em atendimento a este critério, o condomínio conta com eletrodomésticos certificados com o selo Procel instalados em áreas comuns como salão de festas e espaço de convivência dos funcionários. A opção por estes eletrodomésticos com eficiência energética, proporciona redução significativa no consumo de energia mensal.

Critério 1.18 Qualidade de materiais e componentes: Atendendo a este critério, o empreendimento imobiliário contou com matérias de boa qualidade, fabricados por empresas qualificadas, conforme os programas setoriais de qualidade (PSQ) do PBQP-H5. Ao utilizar materiais de boa qualidade durante a construção, foi possível evitar perdas de materiais por defeitos, evitar reparos e manutenções antecipadas. Com isso, reduziram-se os impactos ambientais visto que não foi necessária produção de novos materiais para reposição. 
Critério 1.19 Componentes industrializados ou pré-fabricados: Em atendimento a este critério, as torres do Neo Niterói foram projetadas e construídas de forma estrutural. O prédio foi todo pré-moldado. Por ser um prédio estrutural, as paredes não podem ser quebradas ou modificadas. O fato de ser um projeto todo estrutural tornou-o mais sustentável, visto que diminuiu a perda de matérias e geração de resíduos durante a construção.

Critério 1.20 Formas e escoras reutilizáveis: Em atendimento a este critério, o Neo Niterói contou com formas e escoras reutilizáveis durante toda obra. Por ser um prédio estrutural necessariamente o empreendimento imobiliário precisou ser modelado e construído a partir de formas e escoras específicas para uma construção pré-moldada. O uso de escoras e formas reutilizáveis permitiu a diminuição de desperdícios de materiais, inclusive madeira, visto que as formas e escoras podem ser sempre reaproveitadas e outras construções, assim como foi no neo Niterói.

Critério 1.21 Gestão de resíduos de construção e demolição (RCD): Em atendimento a este critério, durante toda obra do Neo Niterói os resíduos de construção e demolição quando não aproveitados foram devidamente encaminhados ao aterro sanitário local. Ao executar uma boa gestão de RCD, o projeto contribuiu ao não gerar impactos para o meio ambiente urbano.

Critério 1.22 Facilidade de manutenção da fachada: Em atendimento a este critério, na fachada das torres foram utilizadas matérias de boa qualidade que reduzem significativamente a necessidade de manutenção regular. $\mathrm{O}$ aumento de vida útil da fachada, em virtude dos materiais utilizados gerou uma redução de custo com manutenção regular, evitou o desperdício de materiais e consequente diminuição dos impactos ambientais.

Critério 1.23 Dispositivos economizadores - Sistema de descarga: Em atendimento a este critério, o banheiro de cada apartamento possui descarga com dispositivos economizadores de água. Esses dispositivos possuem 2 válvulas de acionamento de água, permitindo maior ou menor volume de água de acordo com a necessidade. Esse sistema permite uma economia significativa de água, pois a maior quantidade de água do reservatório, somente é acionada quando necessário.

Critério 1.24 Dispositivos economizadores - Arejadores: Em atendimento a este critério, na cozinha e no banheiro de cada apartamento do Neo Niterói existe arejador nas torneiras. Esses arejadores das torneiras proporcionam uma redução no consumo de água e facilitam a vida do morador, pois possibilitam uma melhor dispersão do jato de água nas torneiras. 
Critério 1.25 Dispositivos economizadores - Registro regulador de vazão: Em atendimento a este critério, na cozinha e no banheiro de cada apartamento do Neo Niterói existe registros reguladores de vazão. Esses registros de vazão permitem regular a quantidade de água utilizada no apartamento e consequente economia de água do mesmo. Logo, diminui também a quantidade de resíduos de esgoto gerado por cada apartamento.

Critério 1.26 Retenção de águas pluviais: Em atendimento a este critério, o condomínio Neo Niterói conta com canaletas que permitem o escoamento de águas pluviais, evitando possíveis inundações. Esse sistema evita inundações no condomínio e ao entorno e também redução da vazão de águas pluviais contribuindo assim para o sistema de drenagem urbana.

Critério 1.27 Áreas permeáveis: Em atendimento a este critério, o condomínio Neo Niterói conta com áreas permeáveis de acordo com as normas estabelecidas. Essas áreas permeáveis permitem que a água da chuva penetre no solo, renovando assim o ciclo de água da natureza, à medida que a água volta para o lençol freático.

Critério 1.28 Orientação aos moradores: Em atendimento a este critério, durante a entrega das chaves os moradores do Neo Niterói foram devidamente orientados quanto as mais diversas questões voltadas para o bom funcionamento do condomínio. Inclusive foi distribuído o manual do proprietário que conta com informações detalhadas sobre o Neo Niterói. Essa iniciativa proporcionou um espaço para discussão entre os moradores bem como a busca de alternativas mais sustentáveis para o bom funcionamento do empreendimento imobiliário.

Critério 1.29 Educação ambiental dos moradores: Em atendimento a este critério, os moradores receberam o manual do proprietário e uma cartilha, que em especial, apresenta um projeto social voltado para a sustentabilidade do condomínio. Logo, os moradores foram devidamente orientados quanto a educação ambiental. Essa atitude possibilitou práticas mais sustentáveis por parte dos condôminos, o que contribuiu e ainda contribui significativamente para o meio ambiente.

Critério 1.30 Capacitação para gestão do empreendimento: Em atendimento a este critério, os moradores foram previamente orientados a respeito da necessidade de uma gestão administrativa do condomínio. Essa orientação se deu por meio de reuniões e através do manual do proprietário e da cartilha distribuída a todos os moradores. Essa iniciativa permitiu a conscientização dos moradores em relação ao uso e manutenção das edificações de maneira a não prejudicar o meio ambiente. 
Conforme descrito acima, os benefícios adquiridos ao atender os critérios do Selo Casa Azul foram muitos. Ficou claro que são critérios em sua maioria indispensáveis de serem atendidos, caso o projeto tenha por finalidade se adequar dentro de um padrão sustentável. Existe hoje uma necessidade eminente de adequação de projeto a sustentabilidade, projetos residenciais que visem diretamente à preservação dos recursos naturais e do meio ambiente.

O Selo Casa Azul apresenta critérios fáceis de serem atendidos em sua maioria e eficazes em suas propostas.

Os critérios do Selo Casa Azul se atendidos adequadamente, promovem um bom desempenho sustentável do empreendimento imobiliário; não são critério impossíveis de serem atendidos, inclusive de acordo com o guia da Caixa, podemos perceber que são voltados para habitações populares. O importante é pegar previamente um projeto arquitetônico habitacional submeter a uma análise criteriosa para que o mesmo seja adequado as exigências, a fim de pleitear uma certificação do Selo Casa Azul junto à Caixa.

No estudo de caso do Neo Niterói, houve uma pequena dificuldade de identificar documentação que comprovasse a adequação do mesmo a determinados critérios. Alguns critérios foram classificados como não atendidos porque não foi possível validá-lo com a documentação pertinente a comprovação. Essa dificuldade se deu principalmente pelo fato do empreendimento estar construído há mais de 10 anos. Se em realidade fosse intenção pleitear um Selo Casa Azul para o Neo Niterói, seria necessário o condomínio estar passando por alguma obra de acréscimo, modificação ou reforma, pois não é possível pleitear uma certificação sustentável junto à Caixa para um projeto habitacional concluído. O pleito do Selo Casa Azul junto à caixa é possível somente para projetos habitacionais a serem construídos, em fase de construção ou em fase de reforma e acréscimo.

O motivo da escolha do condomínio Neo Niterói como objeto de estudo, foi o fato da identificação prévia de atendimento a muitos critérios estabelecido pelo Selo Casa Azul. Considera-se o Neo Niterói um empreendimento imobiliário praticamente sustentável, mesmo após sua construção ter sido concluída há 10 anos, logo, é possível observar que a dez anos atrás já se pensava em projetos habitacionais sustentáveis que não agredissem tanto o meio ambiente, no entanto, ainda não existia a Certificação Selo Casa Azul da Caixa. 


\section{CONSIDERAÇÕES FINAIS}

Este estudo foi baseado na avaliação do empreendimento imobiliário Condomínio Neo Niterói ante a possível aquisição da Certificação Selo Casa Azul da Caixa Econômica Federal.

De acordo com oguia Selo Casa Azul Boas Práticas para Habitação Mais Sustentável (JOHN e PRADO,2010), ao criar o Selo Casa Azul a Caixa pretende incentivar o uso racional de recursos naturais na construção de empreendimentos habitacionais, reduzir o custo de manutenção dos edifícios e as despesas mensais de seus usuários bem como promover a conscientização de empreendedores e moradores sobre as vantagens das construções sustentáveis.

O Selo Casa Azul é elegível a candidatura de projetos habitacionais de empresas privadas, empresas públicas, cooperativas, associações e entidades representantes de movimentos sociais. A adesão ao Selo é voluntária e o requisitante deve se apresentar a Caixa com toda documentação necessária para avaliação da concessão do Selo Casa Azul. O guia Caixa de Boas Práticas para Habitação Mais Sustentável apresenta todas as instruções necessárias para pleitear uma das gradações do Selo Casa Azul. O guia é bem claro, muito explicativo e de fácil entendimento. O empreendimento imobiliário escolhido neste estudo de caso para análise foi o Condomínio Neo Niterói, foi realizada uma análise minuciosa de todo condomínio através de vistoria no local, verificação de documentos e registros fotográficos, além de vasta pesquisa bibliográfica. Contata-se que o condomínio estaria apto a possível aquisição do Selo Casa Azul na gradação de nível Prata, caso atendesse aos critérios obrigatórios 5.1 (medição individualizada de água), 6.1 (Educação para gestão de RCD) e 6.2 (Educação ambiental dos empregados), no entanto, infelizmente a construção não atende a estas demandas obrigatórias.

Os critérios obrigatórios não atendidos são indispensáveis, pois gerariam grande economia de água; reaproveitamento e destino final adequado dos resíduos de construção e demolição; e também capacitaria todos os profissionais da obra em relação a gestão e educação ambiental. Em uma situação real de pleito frente à certificação sustentável da Caixa, o empreendimento imobiliário estudado, ficaria impossibilitado, pois não se encontra em fase de projeto, não está em fase de construção, nem tão pouco está passando por alguma obra de acréscimo ou modificação. Mas caso o empreendimento imobiliário estivesse em fase de obra, seria possível adequá-lo facilmente de maneira a atender o critério obrigatório 5.1, 6.1 e 6.2 e 
dar entrada na Caixa para aquisição do Selo Casa Azul. Possivelmente seria possível adquirir a gradação no nível Prata da certificação.

Os critérios determinados pelo guia da Caixa são fáceis de serem atendidos por uma construção habitacional, em sua maioria buscam atender níveis básicos de sustentabilidade ambiental. Ao atender os critérios estabelecidos pela Caixa é possível alcançar grande economia financeira durante a construção dos imóveis, diminuir o consumo de matériasprimas, reaproveitar materiais diversos, bem como proporcionar aos futuros moradores economia de água e eficiência energética. Foi possível perceber que grande parte das novas construções habitacionais populares e não populares, poderiam se candidatar a aquisição de uma certificação sustentável Selo Casa Azul junto à Caixa. Essa iniciativa beneficiaria tanto as construtoras, como os compradores e principalmente o Meio Ambiente.

\section{REFERÊNCIAS BIBLIOGRÁFICAS}

AMBIENTE BRASIL. Construções $\quad$ Sustentáveis. $\quad$ Disponível em <http://ambientes.ambientebrasil.com.br/arquitetura/construcoes_verdes/conceito_de_construcao_sustentavel.ht $\underline{\mathrm{ml}}>$ Acesso em 29 de junho de 2014.

BREEM. Disponível em < $\underline{w w w . b r e e a m . o r g}>$ Acesso em 15 de abril de 2015.

BRUNTLAND, Gro Harlem (editor). Our Common Future the World Commission on Environment and Development Oxford. Oxford University Press, 1987.

CIB / UNEP - IETC. The International Council for Research and Innovation in Building and Construction / United Nations Environment Programme International Environment Technology Centre. Agenda 21 for Sustainable Construction in Developing Countries - A Discussion Document. Pretoria, South Africa: CSIR, 2002.

GBC. Green Building Council Brasil.Disponível em <http://www.gbcbrasil.org.br/?p=certificacao > Acesso em 29 de junho de 2014.

JOHN, Vanderley M.; PRADO, Racine T. A. Selo Casa Azul- Boas práticas para habitação mais sustentável. São Paulo: Páginas \& Letras - Editora e Gráfica, 2010. Realização CAIXA ECONÔMICA FEDERAL.

HERNANDES, Thiago Zaldini. FAU - Faculdade de Arquitetura e Urbanismo. LEED-NC como sistema de avaliação da sustentabilidade: uma perspectiva nacional? São Paulo - SP, 2006. 134 f. Dissertação (mestrado) - Área de Concentração: Tecnologia da Arquitetura. Universidade de São Paulo.

LEED. Certificação LEED. Disponível em<http://construcoesverde.blogspot.com.br/2012/03/tecnologia-verde responsabilidade.html> Acesso em 24 de Abril de 2014.

MATTHEWS, Emily; AMANN, Christof; BRINGEZU, Stefan; FISCHER-KOWALSKI, Marina; HÜTTLER, Walter; KLEIJN, René; MORIGUCHI, Yuichi; OTTKE, Christian; RODENBURG, Eric; ROGICH, Don; SCHANDL, Heinz; SCHÜTZ, Helmut; VAN DER VOET, Ester \& WEISZ, Helga. The weight of nations: material outflows from industrial economies. Washington, DC: World Resources Institute, 2000. Disponível em <http://archive.wri.org/publication_detail.cfm? pubid=3023>.Acesso em 24 de Abril de 2014. 
MATOS, Grecia; WAGNER, Lorie. Consumption of materiais in the United States, 1990-1995. Annual Review of Energy and the Environment, v.23, n.1, p. 107-122, Palo Alto, novembro, 1998.

ONU. Conferência das Nações Unidas Sobre Desenvolvimento Sustentável - RIO+20. Disponível em <http://www.rio20.gov.br> .Acesso em: 29 de junho de 2014.

PLAN OF IMPLEMENTATION. World Summit of Sustainable Development. Johannesburg, United Nations. 2002.

RIO92. Disponível em: http://revista.brasil.gov.br/ Acesso em 05/07/2014. Comissão Mundial sobre o Meio Ambiente e Desenvolvimento da ONU. Disponível em < http://www.onu.org.br/> Acesso em 05 de julho de 2014.

ROTH, Caroline das Graças; GARCIAS, Carlos MelloConstrução civil e a degradação ambiental. Desenvolvimento em Questão, v. 7, n. 13, p. 111-128, 2009.

SCHENINI, Pedro Carlos; BAGNATI, Antônio M. Zucatelli; CARDOSO, André Coimbra Felix. Gestão de resíduos da construção civil.In:Cobrac - Congresso Brasileiro de Cadastro Técnico Multifinalitário. Florianópolis: UFSC, de 10 a 14 de outubro de 2004.

WORLD COMMISSION ON ENVIORNMENT AND DEVELOPMENT. Our Common Future Londres: Oxford University Press, 1987. 400 p. 